\title{
VALIDAÇÃO DE INSTRUMENTO DE PESQUISA: PROJETO DE PRODUTO PARA IDOSOS
}

\author{
Vanessa Cristina Libório \\ Universidade do Estado do Rio de Janeiro \\ vanessaliborio88@gmail.com \\ Ligia Maria Sampaio de Medeiros \\ Universidade do Estado do Rio de Janeiro \\ ligia@esdi.uerj.br
}

Resumo: A atuação do designer é reconhecida, em geral, pela resolução objetiva de problemas, equilibrada com o princípio da empatia com potenciais usuários dos produtos ou serviços concebidos e desenhados por aquele profissional. Em sua formação, o designer aprende que soluções adequadas resultam de metodologias projetuais que contemplem a compreensão de interesses, necessidades e dificuldades do ser humano. Para fins comerciais ou acadêmicos, várias são as técnicas de obtenção de informações sobre comportamentos e opiniões de possíveis usuários de um produto. $\mathrm{O}$ argumento da empatia pode parecer livre de contestação, mas cuidados devem ser tomados com participantes de uma pesquisa, ainda que o propósito seja o benefício para futuros usuários. Este artigo apresenta, através de um exemplo, fases de submissão de projeto de pesquisa ao Comitê de Ética em instituição universitária, e discute a conveniência da validação de pesquisa em design na Plataforma Brasil.

Palavras-chave: Ergonomia, Usabilidade, Idosos, Comitê de Ética, Plataforma Brasil

\begin{abstract}
The designer's work is acknowledged by an objective problem solving, balanced with the empathy with potential users of the products or services designed by that professional. In their training, the designers study that suitable and successful solutions result from design methods that include an understanding of people's interests, needs and difficulties. Either for commercial or academic purposes, there are many techniques for gathering information on behaviour and opinions of potential users of a products or services. Although the argument of empathy may seem a consensus, there are safeguards to ensure full respect for the participants in a research. This article presents, through an example, the phases of the submission of a research project to a university ethics committee and its validation in the Plataforma Brasil.
\end{abstract}

Keywords: Ergonomics, Usability, Elderly, Ethics committee, Plataforma Brasil 


\section{INTRODUÇÃO}

A atuação profissional do designer se caracteriza pelo uso de metodologias projetuais específicas e escolha dos procedimentos e técnicas para transformar situações de projeto. Durante a sua formação o designer estuda que não basta o domínio das linguagens tecnológicas e das linguagens para expressão e comunicação de ideias. Ele aprende que soluções com chance de serem bem sucedidas resultam também da capacidade do profissional se colocar na posição de outrem, de entender o sentimento ou a reação de outra pessoa, imaginando-se nas mesmas circunstâncias. Isso fica claro nas definições oferecidas pelo ICSID (International Council of Societies of Industrial Design), inclusive na versão atualizada em 2015 pelo Comitê de Prática Profissional da entidade. Um trecho diz o seguinte: os designers industriais colocam o ser humano no centro do processo; através da empatia, adquirem profunda compreensão das necessidades dos usuários e aplicam um processo pragmático de resolução de problemas centrado no usuário para projetar produtos, sistemas, serviços e experiências. São atores estratégicos do processo de inovação e estão em posição privilegiada para construir pontes entre disciplinas profissionais e interesses comerciais. Valorizam o impacto econômico, social e ambiental com o seu trabalho, e contribuem para a criação de melhor qualidade de vida. (disponível em: http://www.icsid.org/about/about/articles31.htm).

Para fins comerciais e acadêmicos, inúmeras técnicas vem sendo elaboradas para coleta de informações sobre comportamentos e opiniões dos potenciais compradores ou utilizadores de um produto. Técnicas de observação, de escuta e de interação autorizam os pesquisadores a entrarem na vida das pessoas, ouvir suas histórias e obter subsídios valiosos para o projeto. $O$ pesquisador atento, além de compreender os problemas que as pessoas enfrentam, descobre também a inteligência das soluções alternativas, as saídas para a superação dos desafios, e desejos não revelados. $O$ argumento de que a pesquisa visa o benefício social ou do usuário, no entanto, não suplanta o cuidado que se deve ter com a integridade dos participantes. Já é bastante difundido entre designers-pesquisadores o uso do Termo de Consentimento Informado, ou Termo de Consentimento Livre e Esclarecido, para assegurar que os participantes saibam do que se trata o estudo e que sua participação é voluntária. Essa difusão decorreu, em grande medida, da crescente participação de designers em ambientes de pesquisa acadêmica e pela progressiva exigência de periódicos científicos por validação de procedimentos metodológicos. Menos difundida, no entanto, é a submissão de projetos de pesquisa em design a comitês de ética através da Plataforma Brasil.

Este artigo apresenta as fases de submissão de uma das etapas de projeto de pesquisa ao Comitê de Ética de instituição universitária. O projeto previa aplicação da técnica de entrevistas com público idoso que participa de um programa de estudos e atividades voltados para questões inerentes ao envelhecimento. A técnica de entrevista constituía um dos meio de obtenção de dados para a pesquisa e os responsáveis pelo programa de atendimento aos idosos demandaram que o referido projeto cumprisse os protocolos de validação na Plataforma Brasil. A experiência demonstrou que, sendo baseada na tradição da pesquisa em ciências da saúde, a Plataforma Brasil apresenta percalços para o designer-pesquisador, mas é um importante instrumento de profissionalização da pesquisa em design. 


\section{COMITÊS DE ÉTICA NO MUNDO E NO BRASIL}

A discussão sobre valores éticos na medicina é antiga e acompanhou os avanços da ciência, instruindo os limites dos estudos com seres humanos. Avançando um pouco, para ilustrar o cenário no século XIX, pode-se citar Claude Bernard que, em 1865, "afirmou que o princípio da moralidade médica e cirúrgica consiste em nunca realizar um experimento no ser humano que possa prejudicá-lo, mesmo que o resultado seja altamente vantajoso para a ciência" (GOLDIM, 2004).

Após os experimentos brutais com seres humanos realizados por cientistas na Alemanha nazista, o Tribunal de Nuremberg publicou, em 1947, um Código que estabelecia "uma recomendação de repercussão internacional sobre os aspectos éticos envolvidos na pesquisa em seres humanos" (GOLDIM, 2004). Entre as décadas de 1960 e 1990 as discussões prosseguiram em encontros internacionais, abordando a "necessidade de alguma forma de controle externo sobre as atividades de pesquisa envolvendo seres humanos" (BRASIL, 1998 apud TOMANIK, 2008, p. 396). Nota-se que o âmbito do debate cresceu, e seu foco não ficou limitado a experimentos médicos, mas passou a incluir qualquer pesquisa que envolva seres humanos.

No Brasil, a discussão tomou forma em 1988, quando o Conselho Nacional de Saúde - CNS, estabeleceu "que todas as instituições que realizassem pesquisa com seres humanos deveriam ter um Comitê de Ética" (BRASIL, 2015, p. 3). Porém, só em 1996 foi publicada a Resolução CNS n. 196 que criava o Comitê de Ética em Pesquisa CEP, e determinava que um Grupo de Trabalho Executivo, criado pela Resolução CNS $n$. 170 de 1995, fosse responsável pelo processo de criação da Comissão Nacional de Ética em Pesquisa - CONEP. (BRASIL, 2015, p. 3). Dessa forma, foi criado pela Resolução CNS n. 466 de 2012 o Sistema CEP-CONEP, responsável pela "análise ética de projetos de pesquisa envolvendo seres humanos no Brasil [...] baseado em uma série de resoluções e normativas deliberados pelo Conselho Nacional de Saúde, órgão vinculado ao Ministério da Saúde" (BRASIL, s/d). O objetivo do Sistema CEP/CONEP, segundo o Manual de orientação do CNS (BRASIL, 2015, p. 3), é:

proteger os participantes de pesquisa em seus direitos e assegurar que os estudos sejam realizados de forma ética. A eticidade da pesquisa implica, necessariamente, em: 1) Respeitar os participantes em sua dignidade e autonomia; 2) Ponderar riscos e benefícios; 3) Evitar ou reduzir ao máximo os danos que são previsíveis; 4) Ter relevância social; 5) Ser justa e equitativa; 6) Não ser fútil e; 7) Respeitar os direitos dos participantes.

Os CEPs atuam como instâncias dentro das instituições, o que significa que instituições de ensino e de pesquisa possuem um setor próprio para avaliar e dar o parecer seguindo os parâmetros éticos de pesquisa com seres humanos determinados pela CONEP-CNS-Ministério da Saúde. Os CEPs desempenham papel importante para as instituições e para o desenvolvimento científico, pois visam ao "progresso científico e social atrelado ao bem-estar e aos interesses dos participantes das pesquisas" (BARBOSA, 2008, p. 108). Caso a instituição proponente, ou seja, a instituição onde o projeto está sendo desenvolvido, não esteja relacionada a nenhum Comitê de Ética, o projeto de pesquisa é encaminhado à CONEP, para que ela escolha um CEP para fazer 
a análise. Porém, dados mostram que "mais de $98 \%$ das análises e decisões ocorrem a nível local pelo trabalho dos Comitês de Ética em Pesquisa (CEP)" (BRASIL, s/d).

\section{A PLATAFORMA BRASIL}

O envio de um projeto de pesquisa para análise do Comitê de Ética deve ser feito através da ferramenta eletrônica chamada Plataforma Brasil, através do seguinte endereço eletrônico: < $\underline{w w w . s a u d e . g o v . b r / p l a t a f o r m a b r a s i l}>$. Segundo sua definição no site (BRASIL, $s / d$ ), a base é nacional, unificada e traz uma série de facilidades, pois:

permite que as pesquisas sejam acompanhadas em seus diferentes estágios - desde sua submissão até a aprovação final pelo CEP e pela CONEP, quando necessário - possibilitando inclusive o acompanhamento da fase de campo, o envio de relatórios parciais e dos relatórios finais das pesquisas (quando concluídas). O sistema permite, ainda, a apresentação de documentos também em meio digital, propiciando ainda à sociedade o acesso aos dados públicos de todas as pesquisas aprovadas. Pela Internet é possível a todos os envolvidos o acesso, por meio de um ambiente compartilhado, às informações em conjunto, diminuindo de forma significativa o tempo de trâmite dos projetos em todo o sistema CEP-CONEP.

\subsection{Cadastro de pesquisadores, instituição proponente e instituição coparticipante}

Para submeter um projeto de pesquisa ao CEP-CONEP é preciso que o pesquisador responsável e os membros da equipe estejam cadastrados na Plataforma Brasil, assim como a instituição proponente da pesquisa e a instituição coparticipante, se houver. No caso de estudantes de pós-graduação, o mestrando ou doutorando será o responsável pelo projeto de pesquisa, enquanto seu orientador é denominado integrante da equipe de pesquisa. A instituição proponente de pesquisa é a "organização, pública ou privada, legitimamente constituída e habilitada, à qual o pesquisador responsável está vinculado" (BRASIL, 2013, p. 59) e a instituição coparticipante de pesquisa é a "organização, pública ou privada, legitimamente constituída e habilitada, na qual alguma das fases ou etapas da pesquisa se desenvolve" (BRASIL, 2013, p. 59).

No projeto que aqui descrevemos, a instituição proponente é a universidade à qual a pesquisadora está vinculada como estudante de pós-graduação e a instituição coparticipante é a unidade de atendimento ao público idoso, local de realização das entrevistas.

A mestranda (pesquisadora responsável) não possuía cadastrado na Plataforma Brasil, o que foi feito. O cadastro do pesquisador divide-se em cinco tópicos principais: identificação; dados complementares; endereço; anexos; adicionar instituição. Em dados complementares, é preciso identificar seu maior título acadêmico, especialização acadêmica (é preciso escolher entre os cursos de uma lista, porém, design não está entre eles), outros (para ser preenchido se seu curso não estiver na lista anterior, como no caso do design) e o endereço eletrônico do currículo lattes do pesquisador na Plataforma Lattes, do CNPq. Em anexos, é preciso enviar um documento digitalizado, uma foto $3 \times 4$ digitalizada e um currículo, com base no currículo gerado pela Plataforma Lattes, do CNPq. Finalmente, no último tópico, o 
adicionar instituição, é possível vincular seu cadastro a uma instituição de pesquisa. Porém, é preciso que a instituição já esteja cadastrada, assim como o órgão/unidade na qual o pesquisador faz parte. No caso presente, a universidade (instituição) estava cadastrada, mas a unidade a que se vincula o curso de pós-graduação, não estava. Por isso, o cadastro da pesquisadora pôde ser realizado provisoriamente sem vínculo a uma instituição.

Como é preciso estar vinculado a uma instituição cadastrada na Plataforma Brasil para iniciar a submissão do projeto de pesquisa, foi solicitado o cadastro do órgão/unidade, além do cadastro da instituição coparticipante da pesquisa, para que fosse possível editar posteriormente o cadastro da pesquisadora responsável e atribuir vínculo a uma instituição. Tanto o CEP da instituição quanto a própria pesquisadora responsável podem solicitar o cadastro do órgão/unidade na Plataforma Brasil. Assim, a própria pesquisadora responsável preencheu e enviou a solicitação de cadastro do órgão/unidade proponente através da Plataforma Brasil, na seção cadastro. 0 prazo máximo de avaliação e confirmação do cadastro do órgão/unidade é de dez dias, mas, nesse caso, o cadastro foi efetivado em três dias. Da mesma maneira, como a instituição coparticipante da presente pesquisa também não estava cadastrada, foi feita pela pesquisadora responsável uma nova solicitação de cadastro de órgão/unidade, sendo aprovada rapidamente, apenas dois dias depois.

\subsection{Submissão do projeto na Plataforma Brasil}

O pesquisador responsável é o encarregado de enviar o projeto através da Plataforma Brasil. Para isso, é preciso entrar com seus dados e senha para iniciar uma Nova submissão e preencher as seis páginas de submissão do projeto de pesquisa. No caso, foi usado como referencial o guia oferecido pelo COEP/UERJ, disponível no endereço eletrônico http://www.sr2.uerj.br/sr2/coep/Guia submissao pesquisa.pdf.

É possível preencher o cadastro por etapas, ou seja, preencher e salvar, para retornar posteriormente, tornando o processo mais fácil, pois nem sempre o pesquisador tem todos os documentos em mãos para escrever ou anexar à Plataforma. As seis páginas são: informações preliminares; área de estudo; desenho de estudo/apoio financeiro; detalhamento do estudo; outras informações; finalizar.

Na primeira página, informações preliminares, a primeira pergunta refere-se à natureza da pesquisa, pois um projeto para ser analisado pelo Sistema CEP-CONEP deve ter relação com pesquisa com seres humanos, caso contrário, é desnecessária a submissão ao Comitê de Ética. As outras perguntas referem-se às informações sobre o pesquisador principal, os assistentes e a equipe de pesquisa, a instituição proponente e se é um estudo internacional ou não. Com a primeira página preenchida, é possível salvar e/ou avançar a submissão do projeto.

A página dois da submissão do projeto de pesquisa refere-se à área de estudo, onde deve ser informada a Área Temática Especial do projeto. As opções estão divididas em oito áreas relacionadas a pesquisas em genética e reprodução humana; novos fármacos, medicamentos, vacinas, testes diagnósticos, equipamentos, insumos, dispositivos e procedimentos; populações indígenas; biossegurança; e pesquisas com cooperação estrangeira. Como o escopo da presente pesquisa não estava relacionado a nenhuma dessas opções, a Área Temática Especial ficou em branco. Se a CONEP julgar que o projeto merece ser analisado pelo Comitê de Ética, ele será classificado como pertencente à área 09. Já no item Grandes Áreas do Conhecimento, que tem 
como base a classificação do CNPq, foram marcadas Grande Área 4 - Ciências da Saúde, e Grande Área 6 - Ciências Sociais Aplicadas, pois a pesquisa é na área de design, mas trata de artefatos relacionados à saúde para idosos. No item Propósito Principal do Estudo (OMS), foi marcada a opção Ciências Sociais, Humanas ou Filosofia aplicadas à Saúde. Para finalizar a página dois, ainda é necessário o preenchimento do Título Público da Pesquisa, do Título Principal da Pesquisa e qual o nome do pesquisador principal e seu respectivo contato público.

Na página três, a maioria dos campos não foi habilitada para edição, pois não foi marcado nenhum item na página dois que relacionasse a pesquisa diretamente a uma Área Temática Especial. Na presente pesquisa, só foi habilitado para preenchimento na página três os campos Desenho, Financiamento da pesquisa e Palavras-chave.

$\mathrm{Na}$ página quatro deve-se escrever os seguintes elementos do projeto de pesquisa: resumo, introdução, hipótese, objetivo primário, objetivo secundário, metodologia proposta, critério de inclusão, critério de exclusão, riscos, benefícios, metodologia de análise de dados, desfecho primário, desfecho secundário, tamanho da amostra no Brasil, data do primeiro recrutamento, país de origem da pesquisa, número de participantes da pesquisa.

$\mathrm{Na}$ página cinco, é solicitado que se informe se haverá uso de fontes secundárias de dados, o número de indivíduos pesquisados, se o estudo é multicêntrico no Brasil, quais são os demais centros participantes no Brasil, qual a instituição coparticipante, se propõe dispensa do Termo de Consentimento Livre e Esclarecido - TCLE e por quê, se haverá retenção de amostras para armazenamento em banco e por quê, o cronograma da pesquisa, o orçamento financeiro, bibliografia e outras informações que pesquisador responsável queira acrescentar.

Também é na página cinco de submissão de projetos de pesquisa da Plataforma Brasil que é encaminhado o chamado protocolo de pesquisa. Protocolo de pesquisa "é o conjunto de documentos, que pode ser variável a depender do tema, incluindo o projeto, e que apresenta a proposta de uma pesquisa a ser analisada pelo Sistema CEPCONEP" (BRASIL, 2013, p. 8). No presente projeto, por ser uma entrevista semiestruturada, a lista de documentos necessários foi simples. No caso, foram enviados os seguintes documentos: Folha de rosto, TCLE, o projeto de pesquisa original na íntegra e o roteiro da entrevista a ser realizada nesse projeto especificamente.

A folha de rosto é gerada na página cinco de submissão de projeto de pesquisa com os dados do pesquisador responsável e da instituição e órgão/unidade proponentes, de acordo com o que foi preenchido nas páginas anteriores. Essa folha de rosto deve ser impressa e assinada pelo pesquisador responsável e pelo maior responsável pelo órgão/unidade proponente, para, finalmente, ser digitalizada e anexada nessa mesma página onde foi gerada.

O TCLE foi elaborado seguindo o modelo fornecido pela COEP-UERJ, disponível em http://www.sr2.ueri.br/sr2/coep/downloads/Modelo TCLE.pdf. O TCLE é um documento que, segundo Brasil (2015, p. 5), "além de explicar os detalhes da pesquisa (justificativa, objetivos, procedimentos, desconfortos, riscos, benefícios, grupos de alocação, entre outros aspectos), deve informar e assegurar os direitos dos participantes". É recomendável propor um TCLE com as seguintes características, conforme indica Brasil (2015, p. 7): 
conciso, com linguagem fácil, redigido no formato de convite. Deve-se rever cuidadosamente o TCLE em busca de termos técnicos e inapropriadamente empregados ou traduzidos. Termos de consentimento longos e excessivamente detalhados não são desejáveis. O título do documento deve conter a expressão "Termo de Consentimento Livre e Esclarecido".

O participante da pesquisa deve receber uma via do TCLE, assinada e rubricada por ele e pelo pesquisador responsável, assim como o pesquisador responsável deve ficar com uma via assinada e rubricada por ambos. Caso o participante não assine o TCLE por qualquer razão, sua participação na pesquisa deve ser descartada. O projeto de pesquisa foi elaborado seguindo as orientações da Norma Operacional 001 em: http://conselho.saude.gov.br/Web_comissoes/conep/aquivos/CNS\%20\%20Norma\%20 Operacional\%20001\%20-\%20conep\%20finalizada\%2030-09.pdf. Assim, os arquivos foram finalizados e anexados, e pôde-se passar para a página seis da Plataforma Brasil, onde é preciso preencher se é necessário manter o sigilo da pesquisa e por quanto tempo, além de aceitar os termos apresentados pelo Comitê de Ética. Ao clicar no botão Enviar o projeto ao CEP, a submissão é finalizada.

É possível (e aconselhável) acompanhar na Plataforma Brasil o andamento do processo da submissão, para que se verifiquem e se corrijam pendências, além de se tomar ciência da aprovação do projeto. Vale lembrar que para iniciar a pesquisa descrita no projeto, é preciso esperar a aprovação do sistema CEP-CONEP. No presente projeto, após quatro meses, foi recebido o parecer do Comitê de Ética que apontava algumas pendências. A principal delas refere-se ao envio de um documento emitido pela instituição coparticipante, onde a entrevista deve ser realizada, autorizando a pesquisa nas dependências da unidade.

\section{CONCEITOS ÉTICOS EM UM PROJETO DE PESQUISA}

Como mencionada na seção 2 , vários debates internacionais antecederam as diretrizes que apontam a importância do controle externo para pesquisas com seres humanos. O estabelecimento do Comitê de Ética no Brasil seguiu o consenso da comunidade científica internacional sobre o tema. No país, o Ministério da Saúde é o responsável pelas normas e regulação do Comitê de Ética, mesmo que a pesquisa não esteja relacionada com a saúde, sendo necessário apenas que a pesquisa envolva seres humanos. Segundo Tomanik (2008, p. 403), esse papel atribuído ao Ministério da Saúde é importante diante do contexto histórico, e outras áreas do conhecimento podem "complementar ou adaptar as diretrizes apontadas na Resolução [466 de 2012] às suas peculiaridades" (TOMANIK, 2008, p. 403). O Comitê é formado por pesquisadores de diferentes áreas, porém, "é impossível ter representantes de todas as áreas do conhecimento [...] em um único comitê" (SILVEIRA, 2010, p. 390), o que não impede que os projetos sejam deliberados por pares pesquisadores.

Entretanto, alguns autores se opõem à ideia do projeto ser deliberado por um agente externo à pesquisa. De acordo com Silveira (2010, p. 390), "essa profissionalização da ética termina por gerar agentes descomprometidos: aqueles que delegam a outros verificar se suas ações estão de acordo com as regras instituídas". Porém, se for considerado que a necessidade de submeter um projeto de pesquisa à avaliação de seus pares faz com que o pesquisador responsável precise elaborar 
documentos detalhando o seu projeto, apresentando aspectos da pesquisa que muitas vezes são negligenciados ou feitos posteriormente, principalmente em trabalhos acadêmicos, então o quadro é o oposto. Ao enviar um projeto para ser deliberado por terceiros, o pesquisador responsável fica mais atento para que o projeto receba 0 parecer favorável rapidamente e não retorne com pendências e correções a serem feitas. Ele fica ciente das possíveis questões que podem inviabilizar e atrasar sua pesquisa, tornando-se ainda mais comprometido com as questões éticas e com o andamento do projeto desenvolvido sob sua responsabilidade. Além disso, a ética é intrínseca ao indivíduo e "não é a existência de uma regra, externa e anterior ao ato, que rege a decisão ética: é a ponderação do agente, sua reflexão e suas decisões" (TOMANIK, 2008, p. 398).

O objetivo do Comitê de Ética não é impor normas rígidas, e sim trazer para as pesquisas reflexões sobre princípios éticos, "que reflitam os valores e os anseios dos que o elaboraram e dos que o adotarão" (TOMANIK, 2008, p. 400). Sua proposição básica é "proteger a integridade dos sujeitos de pesquisa" (TOMANIK, 2008, p. 403), assim como "respaldar os pesquisadores e a instituição promotora do estudo" (BARBOSA, 2008, p. 116). Ainda, a submissão de um projeto ao Comitê de Ética não exime os pesquisadores de responsabilidades, mas traz garantias maiores que, com a revisão dos seus pares, o projeto segue parâmetros éticos e pode ser realizado sem causar qualquer tipo de prejuízo aos participantes.

\section{O COMITÊ DE ÉTICA E PESQUISAS EM DESIGN}

Os campos de atuação do design são numerosos. É uma profissão inter e transdisciplinar que aproveita a criatividade para resolver problemas e criar soluções melhores para produtos, sistemas, serviços, experiências. Segundo Lessa (2011, p. 27), o caráter interdisciplinar é próprio da cultura projetual em geral. Tal circunstância é consequência do atual contexto social, que demanda novas práticas onde os "limites epistemológicos são relativizados pelo surgimento de tecnologias que englobam aspectos de vários campos, surgem 'conflitos de fronteira', assistem-se à migração e à apropriação de temas de um campo por outros" (LESSA, 2011, p. 27). Essa situação faz que o designer esteja sempre participando de projetos interdisciplinares, com profissionais de outras áreas, desenvolvendo artefatos e conhecimentos com ramificações em temáticas diferentes da sua. O conhecimento obtido nesses projetos interdisciplinares pode gerar conhecimento científico, que deve alcançar os pares pesquisadores de outras áreas, não só os designers. Porém, é oportuno acrescentar que "muitas revistas científicas nacionais vêm adotando a regra de só publicar artigos derivados de processos de pesquisas aprovados por um Comitê de Ética" (TOMANIK, 2008 , p. 403). Da mesma forma, agências de fomento à pesquisa estão exigindo a submissão ao Comitê de Ética de projetos de pesquisa institucional, como monografias e dissertações de mestrado (BARBOSA, 2008, p. 115), o que reforça a importância da submissão dos projetos em design ao Comitê de Ética para os pesquisadores, que precisam de subsídios para a manutenção de seus estudos e atividades.

Para a realização da pesquisa científica, tanto no design quanto em outras áreas, é preciso escolher a população que a pesquisa vai abordar, para, em seguida, "selecionar uma parte representativa dela, denominada 'amostra'" (RUDIO, 2015, p. 62). Vale ressaltar que "a pesquisa científica não está interessada em estudar indivíduos isolados ou casos particulares. Seu objetivo é, antes, estabelecer 
generalizações, a partir de observações em grupos ou conjuntos de indivíduos" (RUDIO, 2015, p. 60). Com esses conceitos em mente, escolhida a população e sua amostra, passa-se para os métodos empregados.

Muitos dos métodos de pesquisa científica utilizados em pesquisas na área do design que envolvem seres humanos já são amplamente empregados por pesquisadores das ciências sociais. Para colocar em prática esses métodos, são aplicados instrumentos de pesquisa, com o objetivo de coletar dados e obter informações ou opiniões da amostra populacional. São muitos os instrumentos de pesquisa passíveis de serem utilizados por designers, e eles são escolhidos "de acordo com o tipo de informações que se deseja obter" (RUDIO, 2015, p. 111). Em comum, eles têm o fato de abordar o ser humano e seus múltiplos aspectos. A seguir, serão apresentados alguns, de forma a ilustrar como o pesquisador e o profissional da área de design comumente realizam pesquisas envolvendo seres humanos, de modo a realizar projetos de acordo com as necessidades dos seus potenciais usuários. Baseado em Moraes (2009, p. 61-62), podemos citar algumas: pesquisa de opinião; pesquisas de atitude; pesquisa de motivação; estudo de caso; pesquisa para análise do trabalho; observação (sistemática e assistemática); registro de comportamento; entrevista; verbalização (depoimento sobre determinada tarefa); questionário; escalas de avaliação, que medem opiniões e atitudes (por exemplo, Escala de Likert); estudo causal comparativo; pesquisa participante; pesquisa-ação; simulações e avaliações através de modelos de testes; testes e experimentos com variáveis controladas.

Consoante o método, o instrumento de pesquisa e sua população/amostra a ser estudada, são determinados os cuidados éticos que devem ser tomados para uma experiência positiva para o pesquisador e para o pesquisado, e que tragam resultados úteis para a pesquisa. O Comitê de Ética pode auxiliar o designer a garantir a idoneidade das pesquisas com o ser humano, como já faz com outras disciplinas.

\section{CONCLUSÃO}

A produção do conhecimento, não importa em qual área, deve seguir parâmetros éticos. O design é voltado para o desenvolvimento de produtos e serviços para as pessoas e, para avançar o seu conhecimento e produzir artefatos adequados às necessidades de determinada população, é preciso aplicar pesquisas envolvendo seres humanos. Mesmo que não sejam pesquisas relacionadas diretamente com a saúde, com tecidos ou materiais humanos, ou que coloquem em risco a integridade física do pesquisado, os métodos de pesquisa utilizados por designers podem, ainda assim, causar constrangimentos aos envolvidos. Como dito anteriormente, o controle ético de um trabalho, seja ele voltado para fins comerciais ou acadêmicos, deve partir daquele que desenvolve o projeto, e não de terceiros, de agentes externos à pesquisa. Mesmo assim, a possibilidade de submeter o projeto ao Comitê de Ética precisa ser considerada, pois o aceite positivo traz sim, diversos benefícios para a pesquisa e para os envolvidos nela. Quando conferido por pares pesquisadores, o projeto ganha credibilidade, relevância e notoriedade entre a comunidade acadêmica, abre-se caminho para que o projeto seja publicado em periódicos científicos de outras áreas e para que os estudantes de iniciação científica e pós-graduação possam receber subsídios das agências de fomento à pesquisa, o processo tende a ser mais organizado, os resultados mais positivos e, principalmente, a experiência para o pesquisado tende a ser melhor. Porém, esse artigo discorreu apenas sobre a ética em uma das fases de 
um projeto, a da pesquisa. É necessário atenção à ética em todas as fases de um projeto. Segundo Lessa (2011, p. 30), o designer deve estar atento à existência de questões como o "respeito pelo consumidor/usuário do artefato projetado. E de modo mais abrangente coloca-se a preocupação com as consequências das atividades empresariais e/ou institucionais" onde cita "questões de ordem holística, como o desenvolvimento sustentável, o equilíbrio ecológico e a reversão de déficits de desenvolvimento social" (LESSA, 2011, p. 30).

\section{REFERÊNCIAS}

BARBOSA, A. S.; BOERY, R. N. S. O.; BARBOSA, A. A. L. A experiência do comitê de ética em pesquisa da Universidade Estadual do Sudoeste da Bahia (CEP/UESB). Rev. Saúde. com, v. 6, n. 2, p. 106-18, 2010.

BRASIL. MINISTÉRIO DA SAÚDE. CONSELHO NACIONAL DE SAÚDE. ABRASCO ASSOCIAÇÃO BRASILEIRA DE PÓS GRADUAÇÃO EM SAÚDE COLETIVA. Cadernos de Ética em Pesquisa, 1998. Disponível na internet por http em: $<$ http://conselho.saude.gov.br/docs/doc_ref_eticapesq/cadernos\%20de\%20etica\%201 .pdf>. Acesso em: 06 mai. 2016.

BRASIL. MINISTÉRIO DA SAÚDE. CONSELHO NACIONAL DE SAÚDE. COMISSÃO NACIONAL DE ÉTICA EM PESQUISA. Manual de orientação: pendências frequentes em protocolos de pesquisa clínica, 2015. Disponível na internet por http em:

<http://conselho.saude.gov.br/Web_comissoes/conep/aquivos/documentos/MANUAL _ORIENTACAO_PENDENCIAS_FREQUENTES_PROTOCOLOS_PESQUISA_CLINICA_V1.pdf >. Acesso em: 21 abr. 2016.

BRASIL. MINISTÉRIO DA SAÚDE. CONSELHO NACIONAL DE SAÚDE. Norma operacional n. 001/2013, 2013. Disponível na internet por http em:

<http://conselho.saude.gov.br/Web_comissoes/conep/aquivos/CNS\%20\%20Norma\%2 0Operacional\%20001\%20-\%20conep\%20finalizada\%2030-09.pdf >. Acesso em: $21 \mathrm{abr}$. 2016.

BRASIL. MINISTÉRIO DA SAÚDE. PLATAFORMA BRASIL. Sobre o sistema CEP/CONEP. s/d. Disponível na internet por http em: <http://aplicacao.saude.gov.br/plataformabrasil/login.jsf>. Acesso em: 20 abr. 2016.

GOLDIM, J. R. Por que relembrar o Tribunal de Nuremberg? Portal Online de Bioética e Ética na Ciência, 2004. Disponível na internet por http em:

<http://www.bioetica.ufrgs.br/nuretrib.htm>. Acesso em: 06 mai. 2016.

ICSID International Council of Societies of Industrial Design. Disponível na internet por http em <http://www.icsid.org/about/about/articles31.htm>. Acesso em: 27 mai.2016.

LESSA, W. D. Objetivos, desenvolvimento e síntese do projeto de design: a consciência do método. In: WESTIN, D.; COELHO, L. A. L. Estudo e prática de metodologia em design nos cursos de pós-graduação. Rio de Janeiro: Novas Ideias, 2011.

MORAES, A.; MONT'ALVÃO, C. Ergonomia: conceitos e aplicações. 4. ed. amp. Rio de Janeiro: $2 A B, 2009$.

RUDIO, F. V. Introdução ao projeto de pesquisa científica. 43. ed. Petrópolis: Vozes, 2015. 
SILVEIRA, R. A. T.; HÜNING, S. M. A tutela moral dos comitês de ética. Psicologia \& Sociedade, v. 22, n. 2, p. 388-395, 2010.

TOMANIK, E. A. A ética e os comitês de ética em pesquisa com seres humanos.

Psicologia em estudo, v. 13, n. 2, p. 395-404, 2008.

UNIVERSIDADE DO ESTADO DO RIO DE JANEIRO - UERJ. SUB-REITORIA DE PÓSGRADUAÇÃO E PESQUISA - SR2. COMISSÃO DE ÉTICA - COEP. Projetos. Rio de Janeiro, 2013. Disponível na internet por http em:

<http://www.sr2.uerj.br/sr2/coep/index.php?mod=projetos.htm>. Acesso em 09 mai. 2016. 